\title{
Der Rollator
}

\section{David Künzler}

Dr. med., Hausarzt im Ruhestand, Mitglied FMH

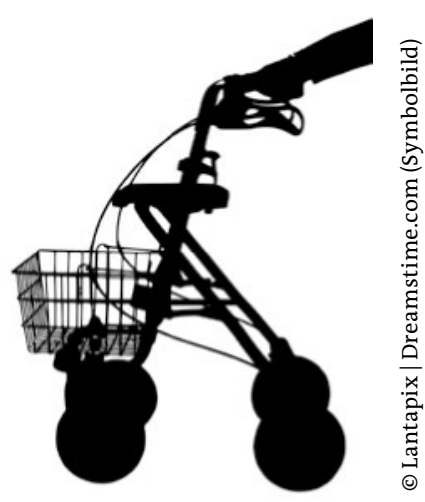

\section{En français «déambulateur», in english "walker»: Der Rollator, eine Gehhilfe von ausgeprägter Kapazität, hat sich international durchgesetzt. Ein Erfahrungsbericht.}

Meine Frau, 80 plus, brauchte infolge zunehmender Schwäche zunächst zwei Stöcke zum Gehen. In der Folge griffen wir auf den Rollator zurück, was sich als segensreich erwies. Wenn «Not am Mann» - lies: an der Frau war, konnte sie jederzeit den Rollator-Sitz nutzen, um sich auszuruhen. Wir machten grössere Spaziergänge in der Umgebung, wobei ich sie immer begleitete, denn es ging doch über Randsteine, bergauf und bergab. Sie meinte, "ich cha das doch elei», doch liess ich sie nicht allein ins Freie, denn zur Bewältigung all der an sich nicht grossen, aber doch zahlreichen Hürden, hätten ihre Kräfte nicht gereicht.

Die Pflege meiner Frau zehrte auch an meinen Kräften. Ich entschied mich ebenfalls für einen Rollator, der sehr hilfreich wurde. Leider verstarb meine Frau bald, und ich trat in ein Pflegeheim ein - als Besitzer von zwei Rollatoren. Die Spitex wollte keinen davon als Occasion übernehmen, doch es eröffnete sich die Möglichkeit, einen in die Ukraine zu senden. Ich nutzte sie gerne und wie ich vernahm, kam der Rollator wohlbehalten dort an.

Nun war ich also Besitzer und Benutzer dieses Instruments, das für viele, die es brauchen könnten, ein «unmögliches» Ding ist. "Ich gsehn dänn jo alt us», hörte ich etwa - dabei war es der oder die Betreffende schon. Ich selber hatte Mühe mit dem Gleichgewicht, benutzte schon lange einen Stock, doch der gab auch keinen guten Halt bei Seitwärtsunsicherheit. Mit dem Rollator konnte ich geradeaus gehen und zwar wesentlich stabilisierter als mit einem oder zwei Stöcken.

Als ich den Rollator meiner Frau gekauft hatte, war ich noch besser in Form gewesen und meinte, man könnte mit diesem «Geriatrietöff» noch den Vitaparcours absolvieren, was ich jahrzehntelang am frühen Morgen praktiziert hatte. Doch letztlich war damit nichts. Mein Rollator war stabil, ziemlich leicht im Gewicht, hatte ein Körbchen für leichtes Gepäck, worin ich schon grössere Sachen transportiert habe, inklusive einige Flaschen Wein. Da ich im Ganzen noch relativ gut zu Fuss, nur wacklig bin, kann ich mich auch im \footnotetext{
Verkehr noch gut bewegen. Auch Ein- und Aussteigen
}

ist bei den heutigen, neuen rollstuhl- und rollatorgängigen Bussen, Trams und Eisenbahnwagen im Allgemeinen gut möglich. Ich lernte auch, an allen Orten nach Liften zu suchen, die für die Vertikalverschiebung doch sehr häufig eingebaut sind. Zwar muss man sie oft "um alle Ecken herum» suchen, aber man kann ja auch fragen. Was ich auch gelernt und erfahren habe, ist die grosse Hilfsbereitschaft der Menschen, insbesondere auch der oft als unhöflich geschmähten Jungen, männlichen wie weiblichen Geschlechts.

Die heutigen Verkehrsmittel des ÖV sind nach meiner halbjährigen Erfahrung im Durchschnitt rollatorfreundlich. Aber es gibt auch Ausnahmen. So hat der Behindertenverband wegen einer ungünstig gebauten Rampe interveniert. Ich habe auch erfahren, dass oft scheinbar kleine Übergänge, die einen Spalt aufweisen, schwierig zu überwinden sind. An den Tottoirrändern gibt es oft kleine Stufen, vielleicht zwei Zentimeter hoch, die nicht einfach zu überwinden sind. Aber überall nahtlose Übergänge zu machen, ist wohl ein Ding der Unmöglichkeit. In solchen Fällen muss man den Rollator halt, zugegeben mit Mühe, etwas anheben. In vielen Eisenbahnzügen gibt es noch sehr hohe Treppen und Einstiege, aber meine Erfahrung ist, dass da immer Hilfe kommt. Alle Wagen in kurzer Zeit rollatortauglich zu machen, ist wohl einfach unrealistisch. Als Rollatorbenützer habe ich versucht, die Perspektiven des Betroffenen und des Arztes zusammenzubringen. Strassenbauern möchte ich ans Herz legen, die Rollatortauglichkeit bei der Realisierung von Projekten bestmöglich zu berücksichtigen. Sehr häufig wird dies bereits gemacht. "Alte Leute» möchte ich dazu ermuntern, ihre eventuelle Scheu vor dem Rollator abzulegen, und last but not least bei häufiger Benützung des ÖV wenn möglich ein Generalbonnement zu lösen. Dann ist man frei, überall hinzufahren und kann ohne Aufwand einund umsteigen. Ich bin schon von Affoltern nach Lugano, nach Basel, Bern und sehr häufig nach Zürich ins Konzert, Kino oder zu anderen Anlässen "gegondelt». 